\title{
Hacked by the Russians
}

\author{
Andre Lamy, MD, MHSc
}

\begin{abstract}
From the Department of Surgery, Division of Cardiac Surgery, McMaster University, Hamilton, Ontario, Canada. Disclosures: A.L. is an investigator for the Aspirin and Tranexamic Acid for Coronary Artery Surgery and the COMPASS trials and Principal Investigator of CORONARY; has no financial disclosure with any health care companies or providers; and is a big fan of Bruce Springsteen.

Received for publication Oct 8, 2018; accepted for publication Oct 8, 2018; available ahead of print Nov 7, 2018 Address for reprints: Andre Lamy, MD, MHSc, Department of Surgery, McMaster University, 237 Barton St East, DBCVSRI C1-112, Hamilton, Ontario L8L 2X2, Canada (E-mail: lamya@mcmaster.ca).

J Thorac Cardiovasc Surg 2019;157:643

$0022-5223 / \$ 36.00$

Crown Copyright $\Subset 2018$ Published by Elsevier Inc. on behalf of The American Association for Thoracic Surgery https://doi.org/10.1016/j.jtcvs.2018.10.025
\end{abstract}

Hacked by the Russians: That was my first reaction when I was asked to review 2 Aspirin and Tranexamic Acid for Coronary Artery Surgery trials for the Journal. I thought the Journal had been hacked or I was reading fake news.

The Aspirin and Tranexamic Acid for Coronary Artery Surgery trial (tranexamic acid vs placebo and acetylsalicylic acid vs placebo in a factorial design) is a great trial that produced 2 factual and honest articles published in The New England Journal of Medicine. ${ }^{1,2}$ No differences in mortality or myocardial infarction (MI) were observed. The same authors are now suggesting that tranexamic acid may reduce major adverse cardiovascular events (MACE) at 1 year (with a $P$ value of .053) and a skimpy meta-analysis showing a reduced rate of MI? How is this possible?

Please try to explain to me how a prothrombotic drug (by stabilizing fibrin clots) could improve survival and decrease MI at 1 year. What is the mechanism? By making more clots? Keep in mind that a large trial ${ }^{3}$ of 27,000 patients just demonstrated that a low dose of antithrombotic medication (rivaroxaban) demonstrated a very significant reduction in MACE (death, MI, and stroke) in patients with coronary artery disease.

You will tell me to let the readers decide for themselves. We are supposed to read the whole article, but most of us only read the title and the conclusion of the abstract, and then if really interested, we will read the whole article. I know you do this as well. There is a reason why people still buy grocery magazines.

Therefore, it is crucial the title, the abstract, and the article represent the data with correct methodology, without trying to sell something or misrepresenting the scientific message. Flashy conclusions and hypotheses have no place in an article. If you have a brilliant hypothesis, just disclose it properly in the Discussion section by mentioning "a trend in improving MACE at 1 year has been observed, possibly explained by avoiding blood products at time of surgery.

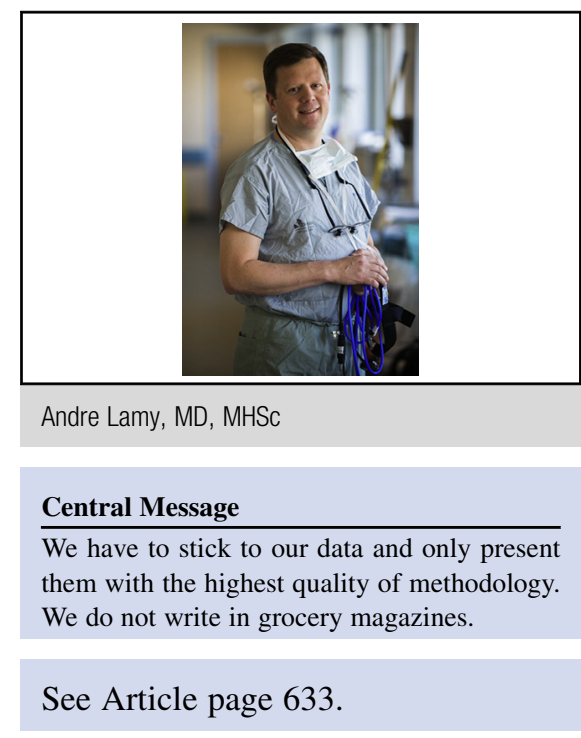

The mechanism remains unclear, but this hypothesis need to be resolved with further research."

It is time that authors put their egos in the closet, avoid over-the-top conclusions, and stick to respected methodology, even if the results are not as expected. ${ }^{4}$ Surgeons are not stupid, but we act like it when we are willing to accept flashy conclusions too quickly, without examining the data but also accepting inaccurate and erroneous articles in our surgical journals. We surgeons, and reviewers and editors as well, need to stick to the facts and demand the highest quality. The authors, reviewers, and editors of The New England Journal of Medicine do it, and this Journal should do it too.

I would like to finish with the words of Bruce Springsteen, a great American songwriter and rocker: "Trust none of what you hear and less of what you see." 5

\section{References}

1. Myles PS, Smith JA, Forbes A, Silbert B, Jayarajah M, Painter T, et al; ATACAS Investigators of the ANZCA Clinical Trials Network. Tranexamic acid in patients undergoing coronary-artery surgery. N Engl J Med. 2017;376:136-48.

2. Myles PS, Smith JA, Forbes A, Silbert B, Jayarajah M, Painter T, et al; ATACAS Investigators of the ANZCA Clinical Trials Network. Stopping vs. continuing aspirin before coronary artery surgery. $N$ Engl J Med. 2016;374:728-37.

3. Eikelboom JW, Connolly SJ, Bosch J, Dagenais GR, Hart RG, Shestakovska O et al; COMPASS Investigators. Rivaroxaban with or without aspirin in stable cardiovascular disease. N Engl J Med. 2017;377:1319-30.

4. Lamy A, Devereaux PJ, Prabhakaran D, Taggart DP, Hu S, Straka Z, et al CORONARY Investigators. Off-pump or on-pump coronary-artery bypass grafting at 30 days. $N$ Engl J Med. 2012;366:1489-97.

5. Springsteen B. Magic. New York, NY: Columbia Records; 2007. 